\title{
Reflexões sobre uma jornada com destino à pesquisa
}

Simone Reis ${ }^{1}$

Universidade Estadual de Londrina

Este artigo resulta de uma retrospecção em minha experiência como formadora de professores com um grupo composto em sua maioria por professores de língua estrangeira que cursaram uma disciplina de Iniciação à Pesquisa em 2001. Recordando-me dos objetivos da disciplina e da metodologia adotada, dos resultados dos alunos e das possíveis causas para esses resultados, meu propósito é estender minhas reflexões a outros envolvidos com a preparação de professores para realizar pesquisa.

This article results from retrospection into my experience as a teacher educator with a group mostly formed by foreign language teachers attending a discipline of Initiation in Research in 2001. By recalling the aims and the methodology adopted in the subject, the outcomes of students and the causes possibly related to these results, my purpose is to extend my reflections to others involved with the preparation of teachers to do research.

No ano de 2001, a Universidade Estadual de Londrina ofertou a primeira turma do curso de Especialização em Ensino de Línguas Estrangeiras, que congregou recém-graduados de cursos de Letras e professores de línguas estrangeiras. Com meu colega, Prof. Otávio Góes de Andrade, conduzi a disciplina intitulada Iniciação à Pesquisa. A contribuição que tínhamos em mente para uma formação continuada dos participantes do curso foi no sentido de (1) dar-lhes suporte ao desenvolvimento de habilidades de estudo, de (2) enfatizar a pesquisa qualitativa, com especial atenção para a pesquisa de sala de aula, e (3) encorajar o desenvolvimento de um projeto de pesquisa que contribuísse para a concretização de uma das exigências acadêmicas

1 Mestre em Lingüística Aplicada (Instituto de Estudos da Linguagem, UNICAMP) e doutora em Ciências Sociais (Graduate School of Education, Radboud Universiteit Nijmegen), centra sua pesquisa na formação de professores de língua estrangeira. 
do curso, a escrita de uma monografia. Neste artigo, resgato o conteúdo tratado por mim visando ao segundo objetivo, a metodologia utilizada para atingir o terceiro objetivo, bem como minhas percepções dos resultados obtidos através dela. A importância desse tipo de registro, na minha opinião, está na centralidade das disciplinas voltadas ao desenvolvimento das habilidades de pesquisa que têm ganhado relevância na formação de professores. Também considero crucial estender a meus colegas docentes minhas reflexões para possível melhoria dos alcances da disciplina Iniciação à Pesquisa.

$\mathrm{Na}$ primeira parte deste artigo, exponho características das pesquisas positivista e qualitativa. Em seguida, apresento princípios da pesquisa de sala de aula. Passo, então, à metodologia desenvolvida no curso para engajar os alunos na elaboração de seus projetos. Depois, trago minhas percepções quanto ao andamento dos projetos à época e discuto alguns fatores que podem ter contribuído para o quadro que ofereço. Finalmente, coloco algumas questões para reflexão coletiva e sugiro tópicos para investigação.

\section{Pesquisa positivista e pesquisa qualitativa}

Uma forma relativamente simples de distinguir a pesquisa positivista da qualitativa é por meio de um raciocínio paradigmático. Guba (1990) emprega o termo paradigma como sendo o conjunto de crenças ontológicas, epistemológicas e metodológicas que guiam as ações do pesquisador. Crenças ontológicas são sobre a "natureza do que é conhecível ou da 'realidade"; crenças epistemológicas, sobre "a natureza da relação entre o conhecedor (o pesquisador) e o conhecido ou conhecível". Crenças metodológicas são a respeito de "como o pesquisador deve buscar o conhecimento" (GUBA, 1990, p. 18).

\section{Pesquisa positivista}

A pesquisa positivista tem suas raízes nas ciências naturais. Fundada pelo filósofo francês Augusto Comte (1798-1857), a corrente de pensamento denominada positivismo tem base ontológica realista; epistemológica, objetivista; e metodológica, experimental ou 
manipulativa. Por influência cartesiana (Descartes, 1596-1650), o pesquisador positivista presume a existência de uma realidade externa, independente, governada por leis naturais de natureza imutável (realismo). A pesquisa busca descobrir a verdadeira natureza da realidade e como ela realmente funciona. Pesquisador e natureza são separados por uma parede de vidro que permite àquele observar esta funcionando sem alterá-la (GUBA, 1990). O método de produzir ciência, teoria ou conhecimento consiste na observação e experimentação (manipulação). Seu objetivo é descrever e explicar um fenômeno, sem, contudo, necessariamente provar sua existência. A concepção de conhecimento é determinista, dogmática e baseada naquilo que se procura: regularidade, previsibilidade e controle. O produto da pesquisa tem de ser uma teoria alcançada por dedução; tem de ser precisa, de aplicação universal e passível de reprodução através do método precisamente descrito. A economia ou parcimônia é um princípio para relatar a teoria gerada. Pressupõe-se que o pesquisador seja neutro em relação ao objeto e contexto da pesquisa, pois, de acordo com o pensamento positivista, a realidade é estável e existe independentemente do pesquisador (COHEN; MANION; MORRISON, 2000).

$\mathrm{Na}$ pesquisa positivista, três critérios para julgamento da pesquisa são adotados: confiabilidade, validade e generalização. Confiabilidade é uma medida de consistência e replicabilidade através do tempo, de instrumentos e de grupos de sujeitos. De uma pesquisa dita confiável espera-se que, dado um grupo de sujeitos semelhante a outro grupo já estudado, os resultados sejam semelhantes aos obtidos neste grupo, mediante uso de instrumentos cuja capacidade de mensuração se considera precisa. Validade tem a ver com a efetividade da pesquisa, que na investigação positivista é compreendida como a capacidade de controlar, de reproduzir, de prever, de gerar leis universais sobre o comportamento humano, de subtrair-se - como pesquisador - do contexto, de submeter os dados à randomização e observação. Generalização é a medida de extensão de aplicabilidade dos resultados para além do grupo estudado.

$\mathrm{Na}$ tradição de pesquisa positivista, a representatividade da amostra sobre a qual são elaboradas as teorias é de grande importância. Assim, estudos que envolvam um grande número de sujeitos ou contextos de um mesmo tipo ou que abranjam uma grande região são bem 
acolhidos. Seus dados são convertidos e reduzidos por meio de fórmulas e assim passam a "representar" o conhecimento sobre a realidade.

\section{Pesquisa qualitativa}

O termo "qualitativo" é amplo demais para definir um estudo. Guba (1990) sugere a explicitação dos princípios adotados para fazer pesquisa através de seu conceito de paradigma. Vários paradigmas de pesquisa foram descritos na literatura. Para uma ampla revisão, sugiro a leitura de Lincoln e Guba (2000). Podendo ser vistos como reações ao paradigma positivista, os paradigmas de pesquisa qualitativa tanto possuem características distintas quanto similares, o que faz com que sejam, até certo ponto, comensuráveis entre si (LINCOLN; GUBA, 2000).

De acordo com Cohen, Manion e Morrison (2000), a pesquisa qualitativa difere da positivista porque seus resultados são derivados de interpretação. Ela está comprometida com a compreensão do mundo subjetivo da experiência humana; seu foco está na ação, i.e., nos significados que as pessoas atribuem aos seus comportamentos e às suas experiências (COHEN; MANION; MORRISON, 2000). O conhecimento é uma forma de compreender e de interpretar o mundo nos termos de seus atores sociais. Estes, pois, são instrumentos da pesquisa e entre eles se inclui o pesquisador (LINCOLN; GUBA, 1985), que também é parte do mundo pesquisado. A neutralidade do pesquisador não é mais do que uma quimera (LINCOLN; GUBA, 2000). O conhecimento não tem a pretensão positivista de ser normativo, porque é interpretativo, necessariamente inacabado, aberto a novas interpretações. A coleta de dados se dá no contexto natural e requer instrumentos que capturem o ponto de vista dos atores sociais: entrevistas, observações, notas de campo, documentos produzidos pelos participantes da pesquisa e gravações de suas interações. As observações têm uma finalidade diferente da empiricista no sentido que, através de longa permanência, possibilitam ao pesquisador familiarizar-se com o contexto observado e com as perspectivas dos participantes. A teoria emerge nos dados e com eles se fortalece, pela busca de significados e propósitos daqueles que são sua fonte (COHEN; MANION; MORRISON, 2000).

Por serem "construções humanas", os sistemas de crenças ou paradigmas "são sujeitos a todos os erros e imperfeições que 
inevitavelmente acompanham os empreendimentos humanos." (GUBA, 1990, p. 19). Na pesquisa qualitativa, os cânones adotados pelo paradigma positivista para julgar a qualidade da pesquisa largamente conduzida nas ciências "duras" foram trazidos para as ciências sociais, onde têm passado por discussão e revisão de seus pressupostos, senão vejamos:

Generalização é um critério positivista que não se aplica à pesquisa qualitativa, porque conflita diretamente com as premissas da pesquisa interpretativista: explorar situações que são idiossincráticas, únicas, situações que não são passíveis de reprodução (COHEN; MANION; MORRISON, 2000). Em outras palavras, "localidade e especificidade são incomensuráveis com generalização" (GUBA, 1990, p. 22).

Confiabilidade e validade são noções em torno das quais critérios alternativos têm sido propostos. Aquela noção não é adequada na pesquisa qualitativa, porque as interpretações são sempre uma representação, uma reconstrução da interpretação dos outros. Portanto, a confiabilidade, cuja preocupação é a reprodução das interpretações através do tempo, entre pessoas e por meio de instrumentos, não faz sentido sob o ponto de vista interpretativo. Com relação à validade, há uma extensa variedade (COHEN; MANION; MORRISON, 2000; LINCOLN; GUBA, 2000). Os tipos mais comuns são a validade interna e a validade externa e dizem respeito tanto aos processos quanto aos resultados das investigações. Também esses são padrões nos quais permeiam influências positivistas, no sentido de que colocam uma necessidade de minimizar a imprecisão dos resultados (validade interna), bem como de conectá-los para além dos limites do contexto e situação investigados, i.e., generalização (validade externa). Por esse motivo, propõem-se critérios alternativos ao de validade para julgamento da qualidade das pesquisas interpretativistas, como, por exemplo, credibilidade (autenticidade).

Credibilidade ou autenticidade (LINCOLN; GUBA, 2000) é um critério segundo o qual um relato de pesquisa pode ser considerado justo, por equilibrar as visões, perspectivas, questões e vozes de todos os envolvidos; por elevar o nível de conscientização dos participantes da pesquisa, primeiramente, e, posteriormente, daqueles com quem têm contato; e por provocar ação por parte dos participantes da pesquisa e o envolvimento do pesquisador em formas específicas de educação 
para ação social e política dos participantes, se assim estes desejarem. Outras formas de validade do relato da pesquisa dizem respeito à honestidade, profundidade, riqueza, escopo dos dados, desinteresse ou objetividade do pesquisador, e extensão de triangulação.

Tanto aspectos como o desinteresse ou a objetividade do pesquisador e a extensão da triangulação revelam preocupações positivistas. Considero desnecessário tecer considerações sobre a inadequação daquele aspecto na pesquisa qualitativa, conforme justifiquei anteriormente, quando me referi à ilusão da idéia de neutralidade do pesquisador. Com relação à triangulação, este é um procedimento adotado por navegadores, pilotos e estrategistas militares, para determinar com precisão a localização de um certo ponto no espaço físico, para isso fazendo uso de mais de um instrumento de medidas (COHEN; MANION; MORRISON, 2000; MILES; HUBERMAN, 1994). A idéia inerente à triangulação é a de confirmação, de determinação precisa. Por analogia, esse raciocínio foi incorporado à prática de pesquisa, através do emprego de "dois ou mais métodos de coleta de dados no estudo de algum aspecto do comportamento humano" (COHEN; MANION; MORRISON, 2000, p.112). Conforme mencionei, a pesquisa qualitativa se ocupa com a ação (comportamento + significados) dos atores sociais e não apenas com seu comportamento. Assim, a adoção de triangulação faz mais sentido nesse tipo de investigação quando o propósito do pesquisador é ganhar maior compreensão do que está sendo estudado e aprofundar suas interpretações. É ilusão do pesquisador procurar "garantir" uma análise objetiva, isenta de parcialidade, subjetividade, preconceitos seus e dos participantes da pesquisa.

Métodos quantitativos são usados na pesquisa qualitativa para servir às finalidades delimitadas pelo pesquisador. A rejeição a métodos quantitativos pode ser compreendida, porém não aceita, pelo fato de que nas denominadas ciências "duras" eles são a base que isenta o pesquisador de dúvida, preconceito e subjetividade. Todavia, não é o tipo de instrumento que se usa que tanto importa, mas o que se faz com os dados que se obtém.

Nesta parte deste artigo, tratei de diferenciar a pesquisa positivista da pesquisa qualitativa, limitando-me a expor seus princípios ontológicos, epistemológicos, metodológicos, bem como abordando seus principais critérios de qualidade de processos e resultados. A seguir, refiro-me à 
pesquisa de sala de aula, à qual dei ênfase durante a realização da disciplina Iniciação à Pesquisa.

\section{A pesquisa de sala de aula}

A pesquisa de sala de aula é definida na literatura como aquela realizada por pessoas envolvidas diretamente com a prática. Nesse universo estão principalmente professores, porém há pesquisa de sala de aula realizada por diretores, coordenadores, entre outros. Basicamente, a pesquisa de sala de aula se ocupa com questões oriundas da prática e com vistas à melhoria dessa prática (CHAUDRON, 1988; 2000; ALLWRIGHT, 1988; NUNAN, 1990; 1992; RICHARDS; NUNAN, 1990; ALLWRIGHT; BAILEY, 1991). É este último elemento a preocupação com a melhoria - que aproxima a pesquisa de sala de aula da pesquisa-ação (NUNAN, 1990; MOITA-LOPES, 1996). A minha opção por enfatizar a pesquisa em sala de aula foi feita por oferecer um leque maior de métodos, inclusive a pesquisa-ação.

Uma revisão da pesquisa em sala de aula mostra que as investigações, até meados da década de 70 no século passado, caracterizavam-se por enfocar as relações entre programas e produto; passaram, então, a enfocar processos e respectivos produtos (CHAUDRON, 2000). Em linhas gerais, investigava-se a relação entre a instrução fornecida pelo professor e resultado de aprendizagem dos alunos. Esse tipo de pesquisa tomava por base a língua como um objeto externo: lidava-se com a língua falada ou escrita como sendo elementos observáveis.

Os desenvolvimentos na Psicologia Cognitiva passaram a se refletir na pesquisa em sala de aula, à medida que técnicas visando a capturar a "língua interna" dos aprendizes foram sendo adotadas e com isso a pesquisa avançou no sentido de revelar processos cognitivos que aprendizes experimentam e que podem favorecer ou restringir sua aprendizagem.

Acompanhando o desenvolvimento social e talvez devido ao insucesso da aplicação de teorias geradas a partir de visões normativas, a pesquisa de sala de aula ampliou seu leque de investigação, passando a se interessar por contextos de ensino e aprendizagem de populações imigrantes, marginalizadas e/ou de grupos minoritários (CHAUDRON, 
2000). Também, a pesquisa de sala de aula mudou no tocante ao professor. De visões que pressupunham que a observação do comportamento de um indivíduo é suficiente para tecer conclusões a respeito de sua ação ou de seu pensamento, a pesquisa passou também a incorporar o pensamento do professor a respeito de sua prática. Gradual e progressivamente, a idéia de fortalecimento do professor através da reflexão sobre sua prática tem se estabelecido no discurso e na prática da formação de professores (CAVALCANTI; MOITA-LOPES, 1991; MOITA-LOPES, 1996; GIMENEZ, 1998) e na própria experiência de professores de língua estrangeira (FIDELIS, 1996; CAMPANÃ, 1996; RAMOS, 1998; CRUZ, 1999; HIRATA, 2000; AMEKO, 2001; BABÓRA, 2000; HESHIKI, 1998; CHERON, 2002; FERREIRA, 2002; LOPES, 2002; POLETTO, 2002; SANCHES, 2002; CAMPOS, 2002; SILVA, 2002).

A idéia de investigação sobre a própria prática, coloquei-a aos alunos da disciplina, apoiando-me principalmente nas concepções de prática exploratória (ALLWRIGHT, 1993) e pesquisa-ação (NUNAN, 1990, MOITA-LOPES, 1996). Na prática exploratória, a investigação decorre da identificação de uma área intrigante, do refinamento do pensamento a respeito daquela área, da seleção de um foco e de procedimentos pedagógicos para explorá-lo; adaptações dos procedimentos à área a ser explorada; interpretação dos resultados, e decisões sobre implicações e ações futuras. Na pesquisa-ação, conforme sugerido por Nunan (1990), a pesquisa se dá por meio de identificação e de investigação preliminar de um problema; formulação de uma hipótese, plano de intervenção; análise e relato do resultado. Na concepção de Moita-Lopes (1996), a pesquisa-ação é um empreendimento a ser realizado por profissionais que trabalham em um mesmo contexto escolar. Segundo esse autor, são eles que definem o problema a ser estudado, negociam os instrumentos de coleta de dados, conduzem sua análise, relatam os resultados da pesquisa em eventos profissionais. O primeiro passo, segundo Moita-Lopes (1996), é a familiarização com os princípios e instrumentos desse tipo de pesquisa. Tanto na prática exploratória quanto na pesquisa-ação está presente a noção de desenvolvimento do professor. A pesquisa, assim, se torna instrumento para desenvolvimento profissional. Foi por esse motivo que a ênfase da disciplina Iniciação à Pesquisa foi dirigida a essas tendências da pesquisa de sala de aula. 


\section{Uma metodologia para o desenvolvimento de projetos de pesquisa}

Ao longo do desenvolvimento da disciplina Iniciação à Pesquisa, um levantamento dos interesses de pesquisa dos alunos do curso foi feito, visando a encaminhá-los o mais cedo possível a seus prováveis orientadores. Após o primeiro contato entre os alunos e o corpo docente, algumas readequações tiveram de ser feitas, a fim de que aqueles se ajustassem aos temas de pesquisa deste. Então, solicitei aos alunos que já atuavam como professores que escrevessem a respeito de sua prática ou de uma questão relacionada ao ensino, de forma que pudessem discuti-la em sala de aula, em grupos. A maior parte dos alunos já atuava no ensino de língua estrangeira. Em sala de aula, examinamos a formulação dos tipos de perguntas de pesquisa e de seu potencial para auto-reflexão (UNDERHILL, 1993). Isso foi feito visando ao início do processo de pesquisa de sala de aula, assim como pensando em facilitar os primeiros passos em direção à orientação de monografia.

Em uma das aulas, utilizei transcrições de uma aula de uma das alunas do curso, com o propósito de engajar o grupo em uma discussão a respeito dos possíveis temas a explorar a partir daquela transcrição. As transcrições da aula foram oferecidas espontaneamente pela aluna, que se graduara no ano anterior em Letras pela Universidade Estadual de Londrina. A iniciativa da aluna e a inserção da escrita de um artigo a respeito de uma questão surgida na prática de estágio supervisionado no referido curso encorajam-me a pensar que ainda na graduação é possível sensibilizar os futuros professores a respeito do papel da pesquisa em sua formação profissional continuada.

Como forma de tornar menos abstrato o conhecimento sobre como fazer pesquisa, convidei algumas ex-alunas que escreveram suas monografias no curso de Especialização em Língua Inglesa da Universidade Estadual de Londrina para relatarem como desenvolveram suas pesquisas. Também, a partir da definição do tópico de interesse dos alunos, reservei uma hora das aulas (de cada 4 horas) para que trocassem entre si as idéias que consideravam relevantes para seu tópico, oriundas de pelo menos um artigo que teriam escolhido por conta própria e lido no espaço de cada uma a duas semanas. Essas atividades foram valorizadas pelos participantes do curso, conforme 
expressaram em seus diários, que mantiveram ao longo da disciplina. Solicitei algumas tarefas com data pré-fixada para definição de tópico da pesquisa, perguntas de pesquisa, instrumentos de coleta de dados, bibliografia inicial, bem como resenha de alguns textos voltados para a própria construção do projeto de pesquisa. Assim procedi, pensando que uma longa jornada é feita de pequenos passos e que, para se chegar ao destino, é preciso tanto querer quanto iniciar a caminhada.

Utilizei os diários dos participantes, que solicitei como instrumento para sua auto-reflexão a respeito de seu aprendizado na disciplina, para obter feedback a respeito do tipo, conteúdo, grau de dificuldade e de satisfação com as atividades desenvolvidas na disciplina. A inserção dos diários foi feita com explicitação dos propósitos, tipos, vantagens, desvantagens de manter um diário, dos tipos de registro feitos e da distinção entre diários puramente descritivos a diários reflexivos. Em dois momentos durante a condução da disciplina, fiz síntese e análise dos diários e as apresentei aos participantes do curso. Elas continham o tipo e predominância de apreciação dos alunos, bem como os fatores relacionados a cada apreciação. Em geral, a maioria expressou apreciação positiva da disciplina em sua concepção, métodos e conteúdo. Expressões de sentimentos negativos foram mínimas e relacionadas a problemas não ligados ao curso (ex.: doença, dificuldade de locomoção, falta de tempo, falta de condições de acesso à tecnologia em suas cidades de origem).

Referi-me, nesta seção, aos tipos, conteúdo, finalidades, e modos de realização das atividades que propus aos participantes do curso como forma de facilitar sua iniciação à pesquisa. A seguir, apresento minhas percepções sobre o andamento dos trabalhos dos alunos em direção ao projeto de pesquisa.

\section{Percepções sobre o andamento dos projetos de pesquisa}

Embora os alunos sempre conversassem em grupos a respeito do andamento de seus projetos, observei que, enquanto alguns sempre realizavam todas as tarefas solicitadas, outros não haviam selecionado textos para seu tópico. Por conseqüência, não haviam feito sua leitura e colocavam-se nos grupos de forma aparentemente passiva e apática; relatavam não terem contatado seu/sua orientador(a), o que, em seu 
entendimento, contribuía para a situação da escrita de seus projetos. Os alunos cujos projetos caminhavam conforme esperado relatavam terem tido encontros com seus orientadores.

Minha percepção à época era a de que talvez tivessem sido poucos os alunos que iriam aproveitar a leitura necessária para a escrita de seu pré-projeto de pesquisa em sua monografia definitiva. Vários optaram por realizar apenas uma revisão da literatura como produto final da monografia, de tal forma que investigações sobre a prática poderiam ficar mais no plano ideal do que na realização prática. Como reflexo, alguns projetos de pesquisa pareciam apenas cumprir uma exigência de avaliação, ao invés de servir de apoio para o desenvolvimento de uma tarefa maior: a pesquisa voltada para seu desenvolvimento.

Se virmos a reflexão sobre a prática como um instrumento para o crescimento profissional, como estratégia de desenvolvimento, a pesquisa pode ser um valioso meio para se chegar a tal fim. Alguns fatores merecem ponderação sobre o que contribui para um tardio engajamento no processo de elaboração de um projeto de pesquisa ou de monografia. Faço essa reflexão implicando-me como docente da disciplina, em primeiro lugar.

Aquilo que entendi ser colocado de forma clara, objetiva e fundamentada nos textos propostos na Inicação à Pesquisa pode ter estado muito distante dos alunos. Minha experiência com pesquisa é obviamente maior do que a dos alunos em função da minha formação e atuação profissional. Porém, isso nada tem a ver com minha capacidade de tornar acessível aquilo que passei a compreender somente pela própria prática de pesquisa. Acreditava que essa forma particular de me tornar pesquisadora pudesse também ser vivida por outros. Dizia à classe, à época, que pesquisa se faz fazendo pesquisa. Dito de outro modo, é preciso fazer pesquisa para entender o que é pesquisa; o tempo de espera para iniciar a pesquisa não favorece o fazer pesquisa diante de um prazo para sua conclusão; é preciso pôr mãos à obra, o que não significa fazer o que vier à mente, sem fundamentação; o pensar, discutir, definir ações, ler, escrever, principalmente não de maneira isolada, mas, na medida do possível, com o suporte de orientação, favorecem a realização da pesquisa.

Talvez minha seleção de textos à época tenha sido equivocada, no sentido de enfocar distinções que considero essenciais ter em mente ao se pensar em fazer pesquisa: natureza do conhecimento, relação entre 
o conhecimento e o conhecedor, e formas de buscar o conhecimento. Entretanto, penso que a opção pela simplificação de textos é também uma redução, daí minha decisão em confiar que o leitor lerá para apreender idéias, não para memorizá-las. Lembrar-se-á de certos detalhes dos textos, encontrará dificuldades que poderá superar com o uso das estratégias de estudo, bem como na sala de aula, um lugar para reconstrução dos textos por parte de todos leitores.

Minha tentativa de tornar o conhecimento sobre fazer pesquisa o mais concreto possível, através de exemplos reais, depoimentos pessoais de ex-alunos, definição de tarefas práticas para serem discutidas e lapidadas em sala de aula talvez tenha ficado ainda assim em um plano abstrato. Diz-se a respeito de aprender a ensinar que a falta de conhecimento prático é fator que restringe a capacidade de alunosprofessores de relacionar suas concepções a suas ações (RICHARDSON; PLACIER, 2001). Essa hipótese poderia ser colocada para a situação de fazer pesquisa: a ausência de conhecimento prático principalmente por meio da experiência torna-se um fator que restringe a associação de idéias relativas à prática de pesquisa. Na Filosofia da Educação, Dewey (1910) ensinou que nossas percepções sobre um objeto são construídas com base na experiência. Talvez minha opção por não interferir e não insistir na eliciação de tópicos de pesquisa de alunos que até o final da disciplina não haviam chegado a uma definição tenha me colocado em uma posição aparentemente distante e desinteressada de suas realidades e necessidades. Minha intenção, contudo, era manter essa prerrogativa a seus próprios orientadores.

Outra consideração a ser feita diz respeito à ênfase à pesquisa de sala de aula. Esse tipo de pesquisa, conforme mencionei, inicia-se com a identificação de uma situação problemática. Isso pode levar mais tempo do que se imagina e requerer condições favoráveis para que a identificação do problema ou questão intrigante seja feita por quem vive a situação e não por alguém que ouve ou lê a respeito dela. Em outras palavras, o desejo de realizar uma mudança deve partir do próprio indivíduo responsável pela mudança e não ser imposto por outrem. Este é um pressuposto de programas de formação de professores que valorizam o desenvolvimento por meio de reflexão. Entretanto, uma conseqüência imediata é a aproximação dos orientadores de pesquisa do tópico escolhido pelo sujeito que irá realizar o estudo e não o contrário. 
Pesquisa em sala de aula pode simplesmente não ter sido o tipo de pesquisa que tanto os alunos da disciplina Iniciação à Pesquisa quanto seus orientadores tenham achado adequada para ser desenvolvida ao longo do curso de especialização e no prazo de um ano. Se este tiver sido o caso, então, realmente, a tarefa de escrita de projeto de pesquisa terá se tornado mais uma mera exigência, com pouca ou nenhuma possibilidade de ter envolvido os alunos em atividades que somassem a seu conhecimento para realizar pesquisa. Reflexão e crítica não são exclusivas da pesquisa de sala de aula, portanto podem ser alcançadas por meio de outra forma de pesquisa qualitativa.

Para finalizar, levo em consideração que cada orientador de pesquisa idealiza um conjunto de conhecimentos e uma metodologia para abordar a iniciação à pesquisa, o que não necessariamente reflete a bagagem de seus pares ou das pessoas que, temporariamente, conduzem uma disciplina para referido fim. É possível imaginar, portanto, que a preparação para iniciar pesquisa possa ser percebida por outros como sendo irrelevante, incipiente, irrealista ou demasiadamente pesada, hermética e complexa para compreensão dos alunos. Tudo irá depender da percepção que cada um tem de seus orientandos, da concepção do que é pesquisa e do que é qualidade na pesquisa, que cada um traz de acordo com sua formação.

\section{Um convite à reflexão coletiva}

Assim como a própria formação de professores que pretende ser reflexiva, a formação de pesquisadores, quer em nível de iniciação, quer em níveis mais avançados, parece sofrer dos mesmos males. O fato de os participantes de uma disciplina relatarem apreciação positiva das atividades não significa que estejam conectando suas ações na direção desejada por quem a conduz. O fato de aproximarem seus projetos aos interesses de pesquisa de seus orientadores não implica igualmente a satisfação dos alunos. De qualquer maneira, a questão que se mantém, vivida no passado, tem em vista o futuro: como tornar o abstrato concreto? Como dar suporte a um engajamento na atividade de pesquisa na qual transpareçam autoconfiança, satisfação e sensação de progresso daqueles a quem desejamos iniciar na pesquisa? 
Ao escrever este artigo, faço-o com o benefício e a limitação que o tempo presente me concede de recordar apenas o que ficou impresso na memória pelo seu valor afetivo (BRUNER, 1990). Propositadamente, fiz referências às pesquisas de pessoas que fizeram de seu trabalho seu objeto de estudo: algumas das professoras-pesquisadoras de cuja formação a Universidade Estadual de Londrina fez parte (FIDELIS, 1996; CAMPANÃ, 1996; RAMOS, 1998; CRUZ, 1999; HIRATA, 2000; BABÓRA, 2000; CHERON, 2002; CAMPOS, 2002; FERREIRA, 2002; LOPES, 2002; POLETTO, 2002; SILVA, 2002). Entre elas estão alunas que cursaram a Iniciação à Pesquisa na turma a que me refiro neste artigo. Talvez se colham frutos importantes de uma investigação sobre como essas professoras-pesquisadoras desenvolveram suas pesquisas, como viram a relação entre sua preparação para pesquisa e a realização de seu estudo; como a experiência de conduzir uma pesquisa se reflete em seu cotidiano da sala de aula; enfim, como construíram seu conhecimento sobre e através da pesquisa e o que isso representa em sua identidade profissional. Finalizo este artigo com essas questões, a forma que mais fielmente revela o estado das minhas certezas.

\section{Agradecimentos}

Um texto é também um resultado de contribuições e encorajamento de outros. Agradeço ao Prof. Otávio Góes de Andrade, pelo estímulo à escrita deste artigo como valorização da experiência na disciplina Iniciação à Pesquisa; à Profa. Denise Ortenzi, por seus comentários à versão preliminar deste artigo e ao Prof. John Robert Schmitz, pela leitura e sugestão de submetê-lo à RBLA. 


\section{Referências}

ALLWRIGHT, D. Observation in the language classroom. London: Longman, 1988. 288p.

Integrating 'research' and 'pedagogy': Appropriate criteria and practical possibilities. In: EDGE, J.; RICHARDS, K. (Ed.). Teachers develop teachers research. Oxford: Heinemann, 1993. p.125-135.

ALLWRIGHT, D.; BAILEY, K. Focus on the language classroom. Cambridge: Cambridge University Press, 1991. 250p.

AMEKO, P. C. O ensino de inglês para crianças não alfabetizadas. $2001.95 \mathrm{f}$. Monografia (Especialização em Língua Inglesa) - Departamento de Letras Estrangeiras Modernas, Universidade Estadual de Londrina, Londrina.

BABÓRA, R. F. Formação reflexiva: relato de uma pesquisa-ação. 2000. 42 f. Monografia (Especialização em Língua Inglesa) - Departamento de Letras Estrangeiras Modernas, Universidade Estadual de Londrina, Londrina.

BRUNER, J. Acts of meaning. Cambridge: Harvard University Press, 1990. $179 \mathrm{p}$.

CAMPANÃ, S. H. A participação do aluno na aula de lingua inglesa na escola pública. 1996. 44 f. Monografia (Especialização em Língua Inglesa) Departamento de Letras Estrangeiras Modernas, Universidade Estadual de Londrina, Londrina.

CAMPOS, R. S. O processo de produção escrita em lingua inglesa e as diferentes formas de feedback. 2002. 47f. Monografia (Especialização em Ensino de Línguas Estrangeiras) - Departamento de Letras Estrangeiras Modernas, Universidade Estadual de Londrina, Londrina.

CAVALCANTI, M. C.; MOITA-LOPES, L. P. M. Implementação de pesquisa na sala de aula no contexto brasileiro. Trabalbos em Lingüistica Aplicada, Campinas, n.17, p.133-144, 1991.

CHAUDRON, C. Second language classrooms: research on teaching and learning. Cambridge: Cambridge University Press, 1988. 221p.

Contrasting approaches to classroom research: qualitative and quantitative analysis of language use and learning. Second Language Studies, v. 19, n.1, p. 1-56, 2000. 
CHERON, M. M. Inserção de uma atividade de produção oral em um processo de ensino aprendizagem de leitura em lingua estrangeira. 2002. $70 \mathrm{f}$. Monografia (Especialização em Ensino de Línguas Estrangeiras) Departamento de Letras Estrangeiras Modernas, Universidade Estadual de Londrina, Londrina.

COHEN, L.; MANION, L.; MORRISON, K. Research Methods in Education. $5^{\text {th }}$ ed. London: Routledge, 2000. 446p.

CRUZ, A. A. A. Refletindo através de meus diários. 1999. 75 f. Monografia (Especialização em Língua Inglesa) - Departamento de Letras Estrangeiras Modernas, Universidade Estadual de Londrina, Londrina.

DEWEY, J. How we think. Boston: Heath, 1910. 224p.

FERREIRA, C. C. Textos literários no processo de ensino/aprendizagem de espanbol. 2002. 77f. Monografia (Especialização em Ensino de Línguas Estrangeiras) - Departamento de Letras Estrangeiras Modernas, Universidade Estadual de Londrina, Londrina.

FIDELIS, R. F. Textos interdisciplinares aplicados em turmas do segundo grau. 1996. 48 f. Monografia (Especialização em Língua Inglesa) - Departamento de Letras Estrangeiras Modernas, Universidade Estadual de Londrina, Londrina.

GIMENEZ, T. Caminhos e descaminhos: a pesquisa na formação de professores de língua estrangeira. The ESPecialist, São Paulo, v. 19, n. 3, p. 257-271, 1998.

GUBA, E. (Ed.) The paradigm dialog. Newburry Park: Sage Publications, 1990. 424p.

HESHIKI, S. R. A. There's more to a training course than trainer and trainee. 1998. 46 f. Monografia (Especialização em Língua Inglesa) - Departamento de Letras Estrangeiras Modernas, Universidade Estadual de Londrina, Londrina.

HIRATA, M. Teacher supervision: a finite set of skills or a socially constructed process? 2000. 60 f. Monografia (Especialização em Língua Inglesa) Departamento de Letras Estrangeiras Modernas, Universidade Estadual de Londrina, Londrina.

LINCOLN, Y. S.; GUBA, E. G. Naturalistic inquiry. Beverly Hills: Sage Publications, 1985. 416p. 
LINCOLN, Y. S.; GUBA, E. G. Paradigmatic controversies, contradictions, and emerging confluences. In: DENZIN, N. K.; LINCOLN, Y. S. (Ed.). Handbook of Qualitative Research. $2^{\text {nd }}$ ed. Thousand Oaks: Sage Publications, 2000. p. 163-188.

LOPES, S. S. R. O espanhol como lingua estrangeira no Ensino Fundamental e Médio. 2002. 62 f. Monografia (Especialização em Ensino de Línguas Estrangeiras) - Departamento de Letras Estrangeiras Modernas, Universidade Estadual de Londrina, Londrina.

MILES, M. B.; HUBERMAN, A. M. Qualitative data analysis: an expanded sourcebook. London: Sage Publications, 1994. 338p.

MOITA-LOPES, L. P. Oficina de Lingüística Aplicada. Campinas: Mercado das Letras, 1996. 190p.

NUNAN, D. Action research in the language classroom. In: RICHARDS, J. C.; NUNAN, D. Second Language Teacher Education. Cambridge: Cambridge University Press, 1990. p. 62-81.

. Research methods in language learning. Cambridge: Cambridge University Press, 1992. 249p.

POLETTO, V.C. Hábitos e estratégias de estudo de alunos de um curso de Letras português-espanhol. 2002. 111f. Monografia (Especialização em Ensino de Línguas Estrangeiras) - Departamento de Letras Estrangeiras Modernas, Universidade Estadual de Londrina, Londrina.

RAMOS, S. M. Cooperative professional development: an experience with EFL teachers. 1998. 58f. Monografia (Especialização em Língua Inglesa) Departamento de Letras Estrangeiras Modernas, Universidade Estadual de Londrina, Londrina.

RICHARDS, J.; NUNAN, D. Second language teacher education. Cambridge: Cambridge University Press, 1990. 340p.

RICHARDSON, V.; PLACIER, P. Teacher Change. In: RICHARDSON, V. (Ed.). Handbook of Research on Teaching. $4^{\text {th }}$ ed. Washington: American Educational Research Association, 2001. p. 905-947.

SANCHES, G. M. M. B. Atividades húdicas no processo de ensino/aprendizagem de espanhol como lingua estrangeira. 2002. 63f. Monografia (Especialização em Ensino de Línguas Estrangeiras) - Departamento de Letras Estrangeiras Modernas, Universidade Estadual de Londrina, Londrina. 
SILVA, K.A.I. Italiano: língua a ser explorada em Pedrinhas Paulista. 2002. 55f. Monografia (Especialização em Ensino de Línguas Estrangeiras) Departamento de Letras Estrangeiras Modernas, Universidade Estadual de Londrina, Londrina.

UNDERHILL, A. Awareness: the instrument and the aim of experiential research. In: EDGE, J.; RICHARDS, K. (Ed.). Teachers Develop Teachers Research: papers on classroom research and teacher development. Oxford: Heinemann, 1993. p. 183-187. 